\title{
Mechanical Properties of High-Nb X80 Steel Weld Pipes for the Second West-to-East Gas Transmission Pipeline Project
}

\author{
Gui-ying Qiao, ${ }^{1,2}$ Xiao-wei Chen, ${ }^{1,3}$ Zhi-en Zhang, ${ }^{4}$ Xiu-lin Han, ${ }^{3}$ Xu Wang, \\ Bo Liao, ${ }^{1}$ and Fu-ren Xiao ${ }^{1}$ \\ ${ }^{1}$ Key Lab of Metastable Materials Science \& Technology, College of Materials Science \& Engineering, Yanshan University, \\ Qinhuangdao 066004, China \\ ${ }^{2}$ School of Environmental and Chemical Engineering, Yanshan University, Qinhuangdao 066004, China \\ ${ }^{3}$ CNPC Bohai Equipment Manufacturing Co. Ltd., Qingxian 062658, China \\ ${ }^{4}$ School of Chemistry and Chemical Engineering, Chongqing University of Technology, Chongqing 400054, China
}

Correspondence should be addressed to Fu-ren Xiao; frxiao@ysu.edu.cn

Received 20 April 2017; Revised 23 August 2017; Accepted 7 September 2017; Published 2 November 2017

Academic Editor: Pavel Lejcek

Copyright (C) 2017 Gui-ying Qiao et al. This is an open access article distributed under the Creative Commons Attribution License, which permits unrestricted use, distribution, and reproduction in any medium, provided the original work is properly cited.

The mechanical properties of steel pipe have great effects on the integrality and operation safety of gas transmission pipeline. In order to reduce the cost of the steel pipe, the high- $\mathrm{Nb}$ X80 pipeline steels with the different alloying systems have been used in the Second West-to-East Gas Transmission Pipeline Project. Nevertheless, an investigation into the effects of chemical composition on the mechanical properties of steel pipes is lacking. In this work, the chemical composition and mechanical properties of high-Nb X80 grade steel pipes with a diameter of $\phi 1,219 \mathrm{~mm}$ and a wall thickness of $22 \mathrm{~mm}$, which are coiled by steels manufactured by three mills, have been analyzed. Furthermore, the effects of chemical composition of the steels on the mechanical properties of the pipe body and weld joint were discussed.

\section{Introduction}

Pipeline transportation is one of the economic ways of oil and gas long-distance transmission. In modern gas pipeline transportation, the developing trend is towards using linepipes of larger diameter and/or higher operation pressure to maximize the transport efficiency and minimize the cost of pipeline construction and gas transportation. This leads to using the higher strength pipeline steel grades to avoid the thicker wall dimensions $[1,2]$. A challenging project is the Second West-to-East Gas Transportation Pipeline Project in China [3]. In this project, the operation pressure of $12 \mathrm{MPa}$ was designed, and the X80 steel pipes with a diameter of $\phi 1,219 \mathrm{~mm}$ and wall thicknesses of 22/26.4/27.5 $\mathrm{mm}$ were used [4]. In order to further reduce the constructing cost, the economic incentive to design the X80 steel with a new concept of high-Nb (>0.06 wt\%) microalloyed has been accepted by the Chinese pipeline industry and Chinese metallurgy community [5]. Many laboratory researches revealed that the high$\mathrm{Nb}$ steels have good strength, toughness, and weldability
[6-9], and they were widely used in manufacturing of highstrength welded steel pipes for the Second West-to-East Gas Transmission Pipeline Project $[4,5]$. However, due to the differences of the rolling mill capacity and the understanding of the effects of alloyed elements and thermomechanical control process (TMCP) parameters on mechanical properties for the different mills, the different alloying systems and content, such as $\mathrm{Mn}-\mathrm{Cr}-\mathrm{Nb}$ or $\mathrm{Mn}-\mathrm{Cr}-\mathrm{Mo}-\mathrm{Nb}$, were designed to manufacture the high-Nb X80 steel plates. As a result, a wide range-fluctuation of the low-temperature impact energy and strength occurred in the steel plates manufactured by different mills or different product batch, which markedly affect mechanical properties of steel pipes, especially the heataffected zone (HAZ) [10].

The large diameter line-pipes are usually manufactured by double-sided submerged arc welding. During welding production, the microstructure of the HAZ adjacent to the weld is greatly upset by the welding thermal cycle [11]. The changes of the microstructure in the HAZ may not only lead to the local brittleness [11] but also decrease the strength $[10,12]$. The 
weakened HAZ will greatly affect the mechanical properties of steel pipe and even the safe operation of pipeline. The major reason is that the initiation and propagation of fatigue crack easily occur in HAZ than in weld metal and base metal [13]. Hence, how to control the mechanical properties of HAZ becomes one of key issues in the researches of pipeline steel. The microstructure and mechanical properties of HAZ strongly depend on chemical composition of the steel and welding parameters $[14,15]$. For the same size steel pipe, the similar welding parameters are generally used in a plant. Therefore, the chemical composition of the steel plays an important role in affecting the mechanical properties of HAZ and steel pipe. Although many lab research works have reported the effect of alloy elements on mechanical properties of HAZ of X80 steel, they mainly focused on the toughness of the coarse grain HAZ (CGHAZ) [15, 16]. Meanwhile, because the HAZ along fusion line of steel pipe is very narrow, the sample of HAZ for the impact test may include other zones such as fine grain HAZ (FGHAZ), intercritical HAZ (ICHAZ), and even base metal (BM), which may affect the impact energy of HAZ of steel pipe.

In addition, for the microalloyed pipeline steel with multiple alloyed elements, the little changes of one alloyed element may greatly affect the mechanical properties of HAZ $[10,16]$. Therefore, it is difficult to evaluate accurately the effect of each single alloyed element. Thus, the carbon equivalent (CE) methods suggested by different institutions, for example, International Institute of Welding (IIW), Japanese Ito (ITO), American Welding Society (AWS), Japanese Industrial Standards (JIS), and German Welding Society (DVS), are introduced to evaluate the weldability of steels. Among these CE methods, the CEs of Ceq and Pcm suggested by IIW and ITO as the most common methods are used in API Specification 5L (API, American Petroleum Institute) and specification of the technical conditions of the hot rolling steel plate for the Second West-to-East Gas Transmission Pipeline Project [5].

In this work, the chemical composition and mechanical properties of the $\Phi 1219 \mathrm{~mm} \times 22 \mathrm{~mm}$ steel pipe made of the high-Nb X80 pipeline steel plate manufactured by three steel mills were reported. Furthermore, the effects of chemical composition on mechanical properties of pipe body and weld joint including weld metal and HAZ were discussed on the basis of the Ceq and Pcm used in the technical conditions of the hot rolling steel plate for the Second West-to-East Gas Transmission Pipeline Project. These results will provide a basic data for evaluating the integrality and operation safety of the second west-to-east gas pipeline, as well as directing the research and development of high-Nb pipeline steels.

\section{Sample Selection and Actual Manufacture Processes of Weld Pipes}

Total 559 batches of welded steel pipes of outer-diameter of $1219 \mathrm{~mm}$ and wall-thickness of $22 \mathrm{~mm}$ made of the high$\mathrm{Nb}$ X80 pipeline steel plate manufactured by three steel mills were selected in this statistical investigation. Among them, 206 batches are from A steel mill, 54 batches are from B steel mill, and 299 batches are from C steel mill, respectively. The steel pipes were manufactured by "JCOE" deformation processes, that is, being deformed by "J" press, afterwards "C" press, and then "O" press, finally expanding (JCOE), which are clearly illustrated in Figures $1(a)-1(d)$. The formed plates were welded to produce the pipe. The fourwire tandem submerged arc welding (TSAW) was employed for manufacturing the heavy thickness steel pipe. During the welding stage, the double-V joints were prepared, continuously prewelded, and then welded by inside and outside double-sided submerged arc welding. Consumables of $\mathrm{Mn}$ Mo-Ti-B welding wire with a diameter of $4 \mathrm{~mm}$ and fluoride alkali high toughness sintered solder were also used. The total heat input from the sum of all electrodes was calculated, which is higher than $4.0 \mathrm{~kJ} \mathrm{~mm}^{-1}$.

The specimens of mechanical properties were cut from the pipes. The strength and low-temperature toughness of pipe body and welding joint were tested according to the standard for the Second West-East Pipeline Project. The sampling location and sample shape are illustrated in Figures $1(\mathrm{e})-1(\mathrm{i})$.

\section{Results of Statistical Investigation}

3.1. Chemical Composition of the Steels. The X80 steels manufactured by the three mills for the Second West-to-East Gas Transmission Project are designed with low-C, high$\mathrm{Mn}$, and high-Nb systems; besides, they are also added with other alloying elements such as $\mathrm{Cr}, \mathrm{Mo}, \mathrm{Ni}$, and $\mathrm{Cu}$. Figure 2 shows the distribution of $\mathrm{C}$ and alloying elements of $\mathrm{Mn}$, $\mathrm{Nb}$, and $\mathrm{Cr}-\mathrm{Mo}-\mathrm{Ni}-\mathrm{Cu}$ of the steels from different mills. The content of $\mathrm{C}$ in the steels is in a range from 0.03 to $0.07 \%$ (Figure 2(a)); the content of $\mathrm{Mn}$ is in a range from 1.64 to $1.94 \%$ (Figure 2(b)); the content of $\mathrm{Nb}$ is in a range from 0.60 to $0.11 \%$ (Figure $2(\mathrm{c})$ ). The content of other alloying elements of $\mathrm{Cr}+\mathrm{Mo}+\mathrm{Ni}+\mathrm{Cu}$ is in a range from 0.60 to $0.11 \%$ (Figure 2(d)). Some differences can be clearly found because of different mills (Figure 2). For example, the steels from mill A have the lower amounts of $\mathrm{C}, \mathrm{Mn}, \mathrm{Cr}+\mathrm{Mo}+\mathrm{Ni}+\mathrm{Cu}$, and the higher amounts of $\mathrm{Nb}$; their mean amounts of $\mathrm{C}$, $\mathrm{Mn}, \mathrm{Cr}+\mathrm{Mo}+\mathrm{Ni}+\mathrm{Cu}$, and $\mathrm{Nb}$ are $0.043 \%, 1.722 \%, 0.598 \%$, and $0.090 \%$, respectively. While the steels from mill $\mathrm{C}$ have the higher amounts of $\mathrm{C}, \mathrm{Mn}, \mathrm{Cr}+\mathrm{Mo}+\mathrm{Ni}+\mathrm{Cu}$, and the lower amounts of $\mathrm{Nb}$; their mean amounts of $\mathrm{C}, \mathrm{Mn}$, $\mathrm{Cr}+\mathrm{Mo}+\mathrm{Ni}+\mathrm{Cu}$, and $\mathrm{Nb}$ are $0.055 \%, 1.812 \%, 0.763 \%$, and $0.076 \%$, respectively.

On the other hand, for the steel of mill A, there are the two distribution peaks of the amount of $\mathrm{Nb}$ and $\mathrm{Cr}+\mathrm{Mo}+\mathrm{Ni}+\mathrm{Cu}$ in Figures 2(c) and 2(d). The peaks of amounts of $\mathrm{Nb}$ appear at about $0.065 \%$ and $0.010 \%$, respectively, while the peaks of amounts of $\mathrm{Cr}+\mathrm{Mo}+\mathrm{Ni}+\mathrm{Cu}$ appear at about $0.55 \%$ and $0.75 \%$, respectively. This is because of two kinds of chemical composition system of the high- $\mathrm{Nb}$ X80 steels of mill $\mathrm{A}$, that is, the $\mathrm{Mn}-\mathrm{Cr}-\mathrm{Nb}$ and the Mn-Cr-Mo-Nb systems. On the contrary, the high- $\mathrm{Nb}$ X80 pipeline steels of mill B and C are only the Mn-Cr-Mo-Nb system. Nonetheless, the content of Mo for all steels is very low, which is only about $0.10 \%$, and lower than the X70 steel developed before. The aim is to reduce the cost of the X80 pipeline steels. 

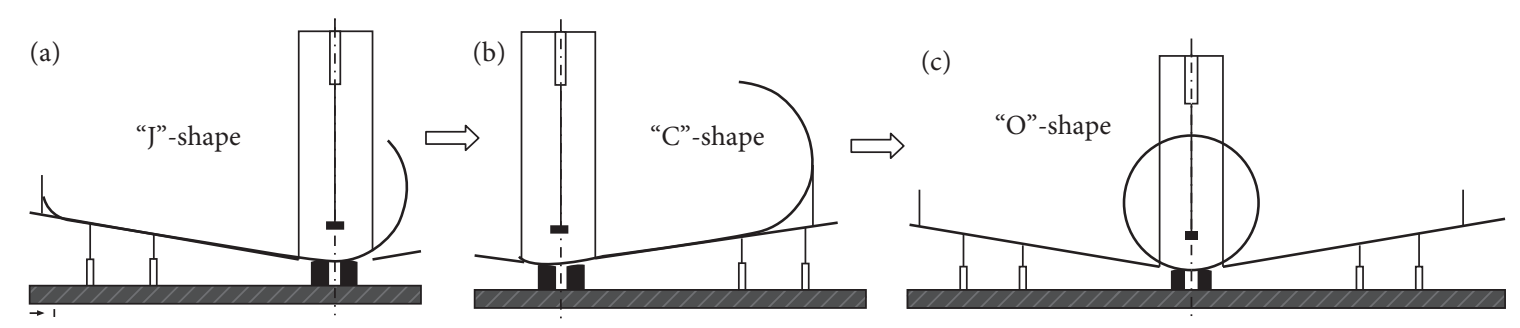

(f)
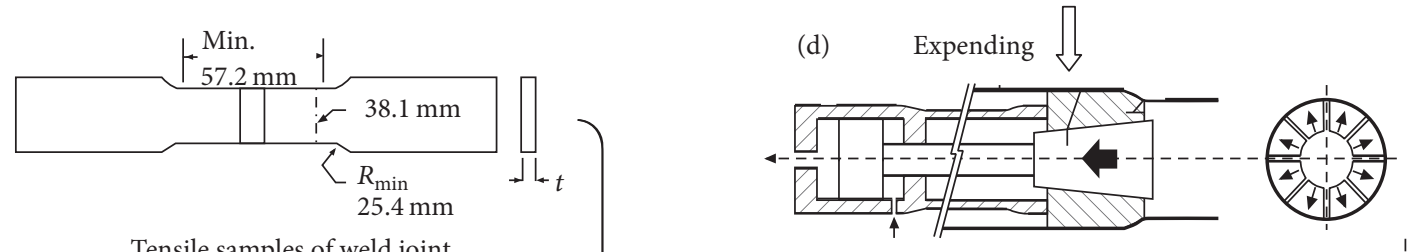

(g)

Tensile samples of weld joint

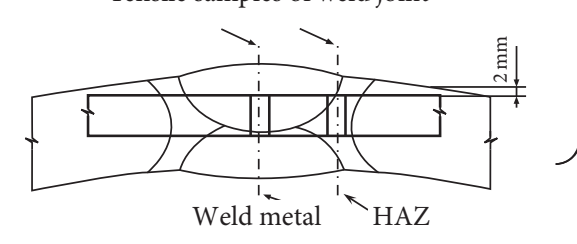

Impact samples of weld metal and HAZ

(h)

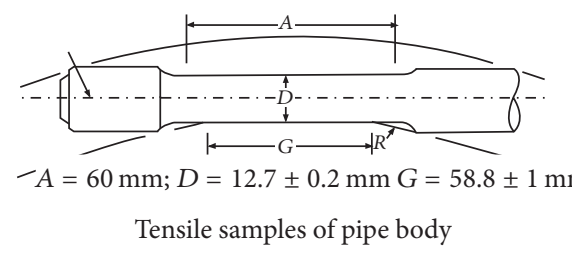

(i)

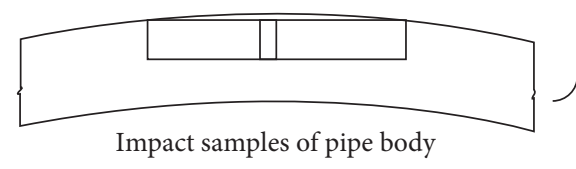

(e)
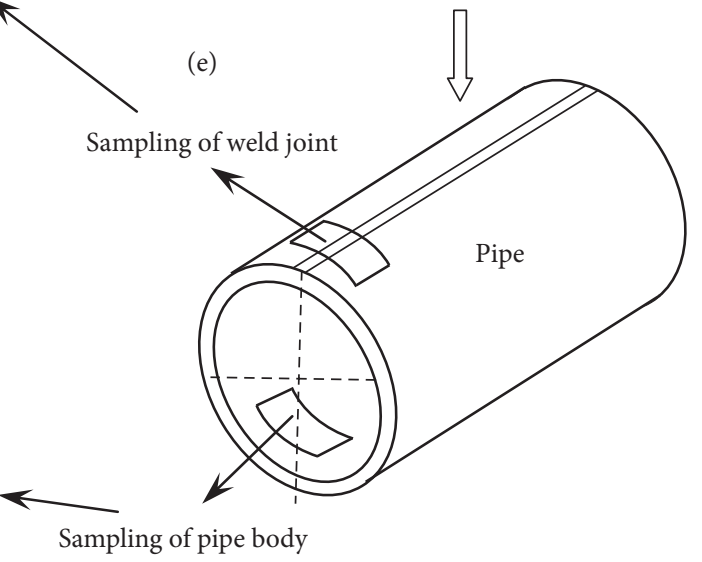

Sampling of pipe body

FIGURE 1: Sketch map of JCOD forming processes (a)-(d); the sampling location and sample shape of pipe body and weld joints (e)-(i).

3.2. Mechanical Properties of the Pipe Body. Figure 3 shows the statistic results of mechanical properties of pipe body. All steels have the high strength and toughness, which meet the specified requirements of the technical conditions of the longitudinal submerged arc welded pipe for the Second Westto-East Gas Transmission Pipeline Project [4]. As can be seen from Figure 3, the statistic results of the strength match the normal distribution. The mean yield strengths of steels from mills $\mathrm{A}, \mathrm{B}$, and $\mathrm{C}$ are $625 \mathrm{MPa}, 618 \mathrm{MPa}$, and $637 \mathrm{MPa}$, respectively, and the tensile strengths are $687 \mathrm{MPa}, 676 \mathrm{MPa}$, and $723 \mathrm{MPa}$, respectively. Meanwhile, the varied ranges of the strength are very large for the steels from mill A and mill $\mathrm{C}$, which is over $110 \mathrm{MPa}$, while the variation range of strength for mill $\mathrm{B}$ is narrow, which is about $85 \mathrm{MPa}$ (Figures 3(a) and $3(\mathrm{~b}))$. These results indicate that the chemical compositions of steels have a great effect on strength. The total amount of alloyed elements of the steels from mill $\mathrm{C}$ is larger than that of the steels from mill A (Figure 2); as a result, the strength is improved; simultaneously, the yield ratio decreases (Figure 2(c)). Nonetheless, the chemical composition is not only one of the factors to affect the strength. For example, comparing to the steels of mill A, the amount of alloyed elements in the steels from mill B is higher (Figure 2), but they have near strength.

On the other hand, the pipe bodies coiled by the high-Nb steels have the excellent low-temperature impact toughness (Figure 3(d)). The average impact energies of the steels manufactured by mills A, B, and C are $383 \mathrm{~J}, 435 \mathrm{~J}$, and $265 \mathrm{~J}$, respectively. Moreover, the low-temperature impact toughness strongly relates to the chemical composition of the steels. For example, the two distribution peaks of the toughness are detected for steels manufactured by mill A, which may be related to two kinds of chemical composition of X80 steels, that is, Mn-Cr-Nb system and Mn-Cr-Mo-Nb system by contrasting the results of distribution of $\mathrm{Nb}$ and $\mathrm{Cr}+\mathrm{Mo}+\mathrm{Ni}+\mathrm{Cu}$ (in Figures 2(c) and 2(d)). Additionally, the steels from mill $\mathrm{B}$ have the highest values of impact energy (Figure 3). These results indicate that the optimum content of alloy seems to corresponding higher impact energy.

3.3. Mechanical Properties of Weld Joint. For the X80 weld pipes, the tensile strength of the weld joint and the impact toughness of heat-affected zone and weld metal must be measured. Figure 4 displays the statistic results of the 


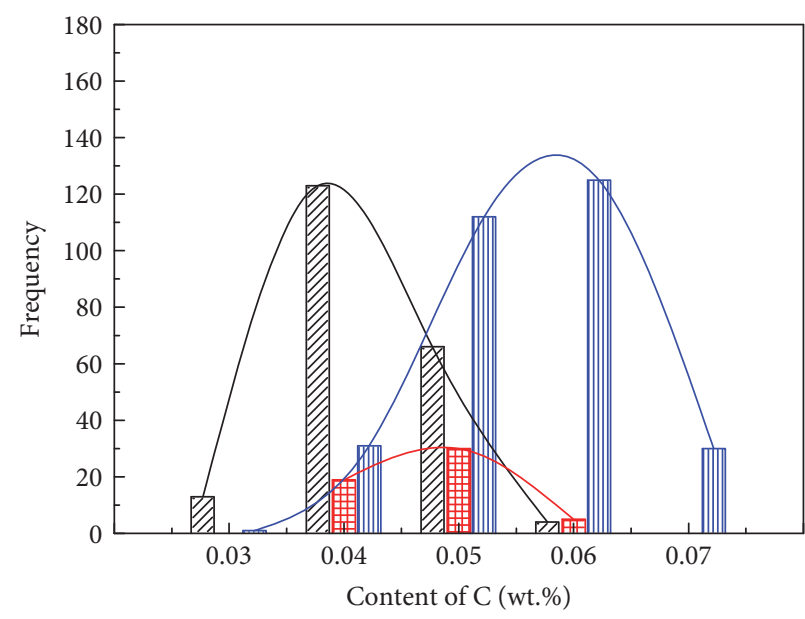

VII Mill A: $N=206 ;$ mean $=0.043$

Mill B: $N=54$; mean $=0.047$

盂血 Mill C: $N=299$; mean $=0.055$

(a)

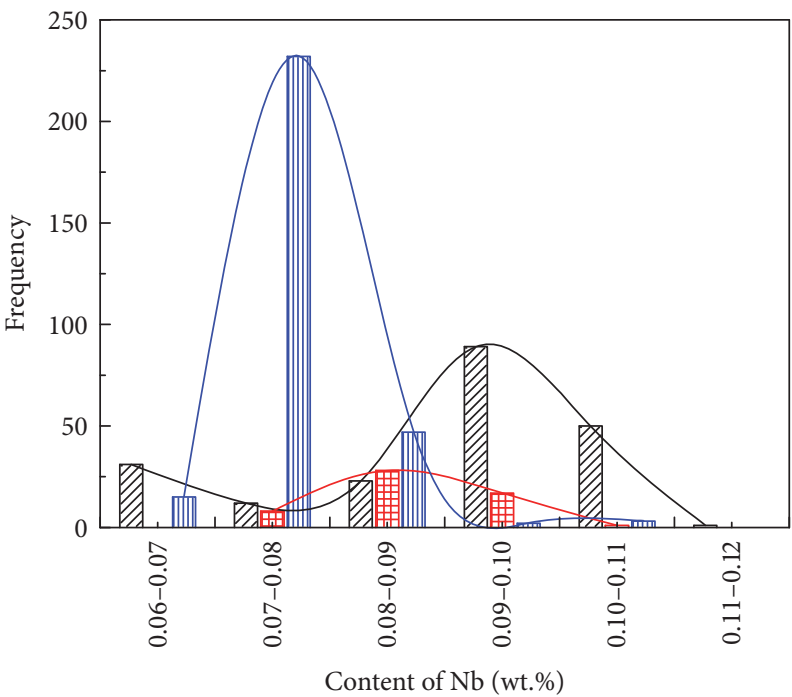

Mill A: $N=206 ;$ mean $=0.090$

Mill B: $N=54$; mean $=0.089$

而血 Mill C: $N=299$; mean $=0.076$

(c)

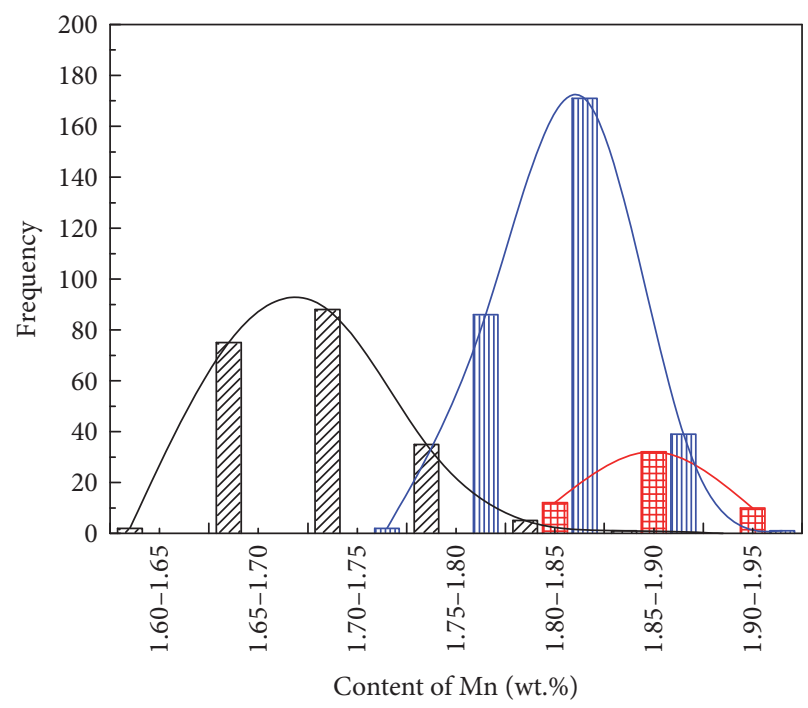

WIII Mill A: $N=206$; mean $=1.722$

Mill B: $N=54$; mean $=1.876$

血血耑 Mill C: $N=299$; mean $=1.812$

(b)

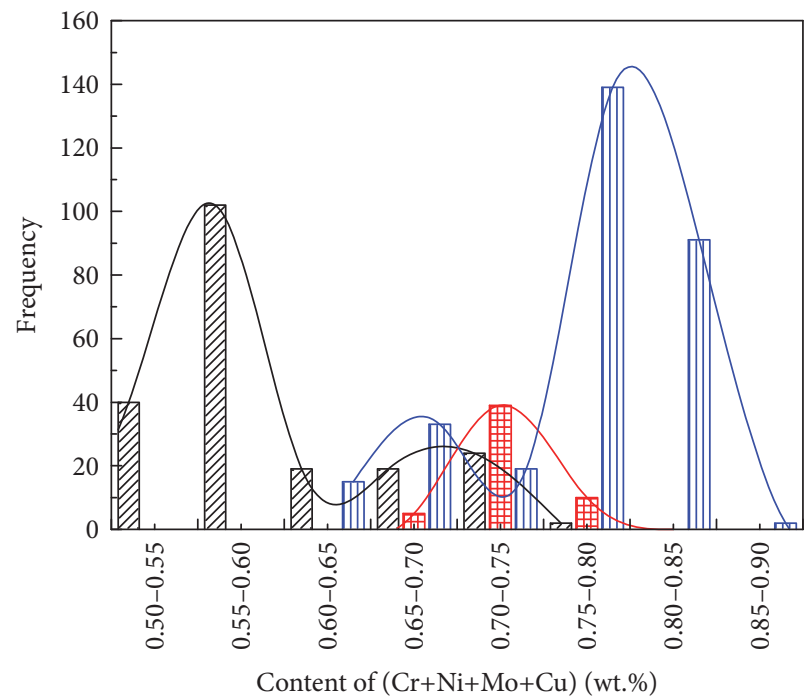

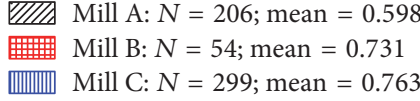

(d)

Figure 2: Distribution histogram of C and alloying elements in the steels from different mills: (a) C; (b) Mn; (c) Nb; (d) Cr-Mo-Ni-Cu.

mechanical properties of the weld joints. The mechanical properties of the weld joints of the three mills match the normal distribution. Their mean tensile strengths of steels manufactured by mills A, B, and C are $690 \mathrm{MPa}, 709 \mathrm{MPa}$, and $718 \mathrm{MPa}$, respectively (Figure 4(a)). The mean impact energy is $293 \mathrm{~J}, 324 \mathrm{~J}$, and $219 \mathrm{~J}$, respectively (Figure 4(b)), and the mean impact energy of the weld metal is 174,158 , and $184 \mathrm{~J}$, respectively (Figure $4(\mathrm{c})$ ). Some changes of the tensile strength and impact toughness of the weld joint can be found by comparing with the pipe body (Figures 3(b) and $3(d)$ ), since the weld process disorganizes the mechanical properties of the HAZ. The distribution of tensile strength of the weld joint is more concentrated, and its mean tensile strength increases with the increasing of amount of alloying element (Figure 4(a)). While the Charpy impact energy of $\mathrm{HAZ}$ obviously decreases, the average impact energy reduces about 50 110 J compared to that of the pipe body. In addition, for the steels of mill $\mathrm{A}$, the two distribution peaks of the impact energy disappear (Figure 4(b)). These results indicate that the chemical compositions have an important effect on the mechanical properties of HAZs. Therefore, there may be an optimum chemical composition range to obtain high 


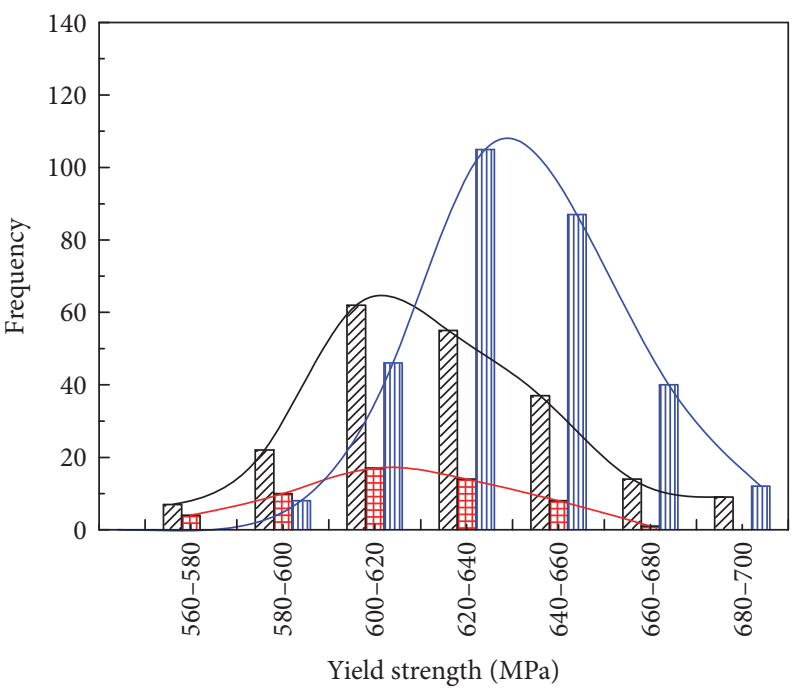

Mill Mill A: $N=206 ;$ mean $=625$
Mill B: $N=54 ;$ mean $=615$
Mill C: $N=299 ;$ mean $=637$

(a)

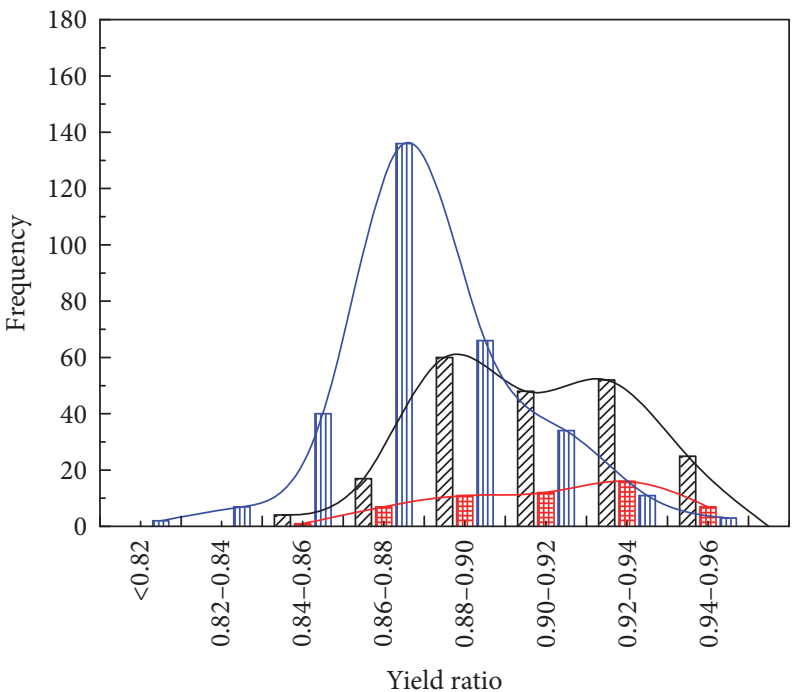

VIIII Mill A: $N=206$; mean $=0.910$

Mill B: $N=54$; mean $=0.910$

血耑 Mill C: $N=299$; mean $=0.882$

(c)

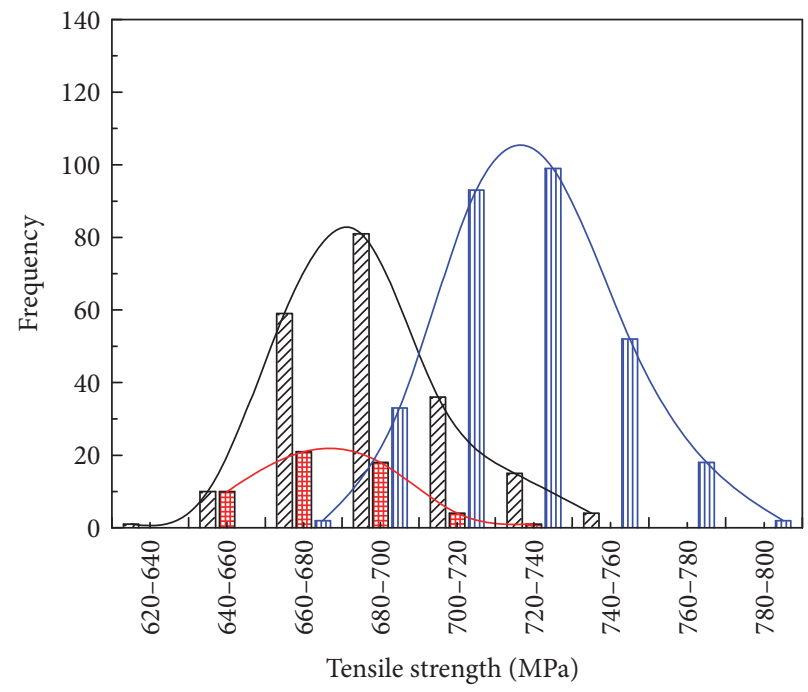

VIII Mill A: $N=206 ;$ mean $=687$

Mill B: $N=54$; mean $=676$

盂耑 Mill C: $N=299 ;$ mean $=723$

(b)

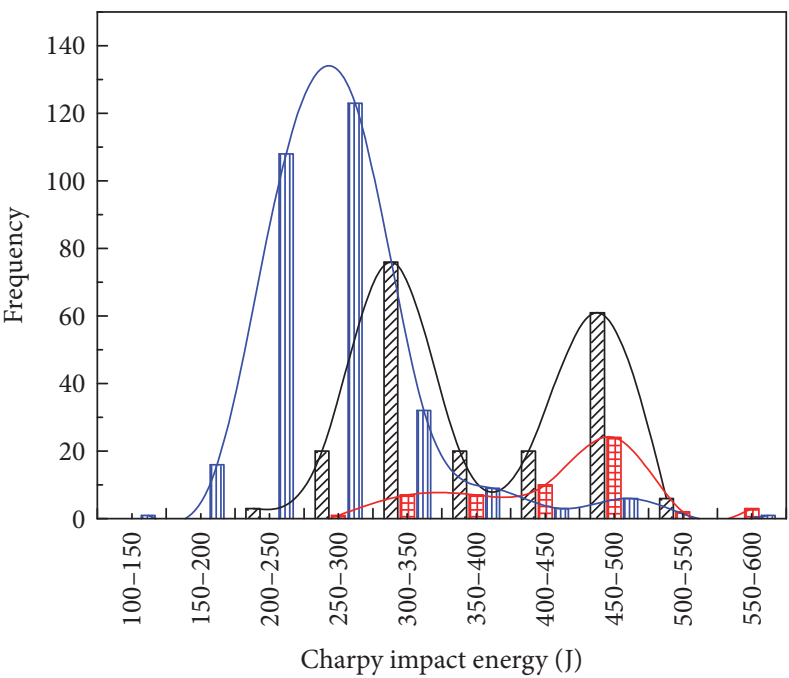

VIIII Mill A: $N=206$; mean $=293$

Mill B: $N=54 ;$ mean $=435$

血血 Mill C: $N=299 ;$ mean $=265$

(d)

FIGURE 3: Histogram of mechanical properties of the pipe bodies: (a) yield strength; (b) tensile strength; (c) yield ratio; (d) Charpy impact energy.

toughness in HAZ under the condition of certain welding process.

\subsection{Effect of Carbon Equivalent on Mechanical Properties.} The above results show that the mechanical properties of pipe body and weld joint (weld metal and HAZ) are strongly correlated to the chemical composition of the steels. The chemical composition of the high-Nb-X80 pipeline steel plays an important role to affect the mechanical properties of the weld steel pipe. The results of statistical analysis from Figures 2-4 indicate that the strength of pipe body and weld joint increases with the increasing of total amount of $\mathrm{C}$ and alloy elements, such as $\mathrm{Mn}, \mathrm{Cr}, \mathrm{Ni}, \mathrm{Mo}$, and $\mathrm{Cu}$. For the impact toughness of the pipe body and HAZ, there seems to be an optimum amount of $\mathrm{C}$ and alloy elements, especially in HAZ. However, for the steels manufactured by different mills, because the distribution of the mechanical properties is in a very large range, it is difficult to seek out their rule.

The carbon equivalent (CE) method is one of the most common and easiest methods to research the weldability of steels. Therefore, the CEs of Ceq and Pcm suggested by International Institute of Welding (IIW) and Japanese Ito 


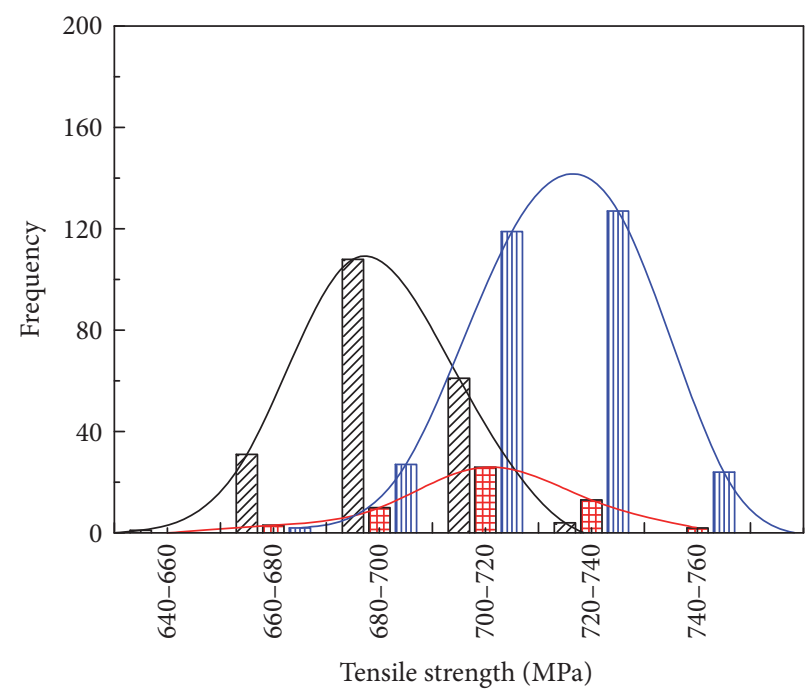

Mill A: $N=206 ;$ mean $=691$
Mill B: $N=54 ;$ mean $=709$
向盂 Mill C: $N=299 ;$ mean $=718$

(a)

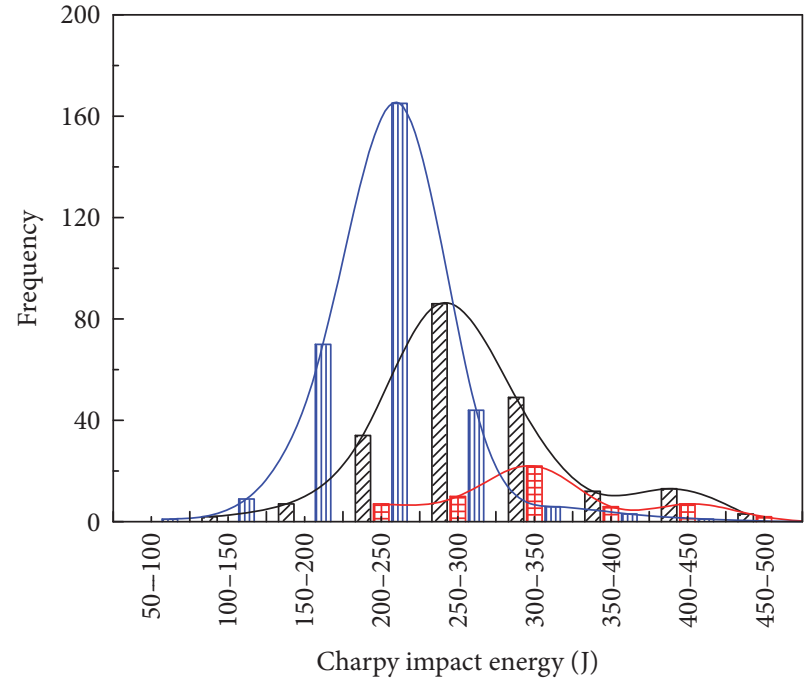

VIII Mill A: $N=206 ;$ mean $=293$

曹冊 Mill B: $N=54$; mean $=324$

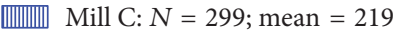

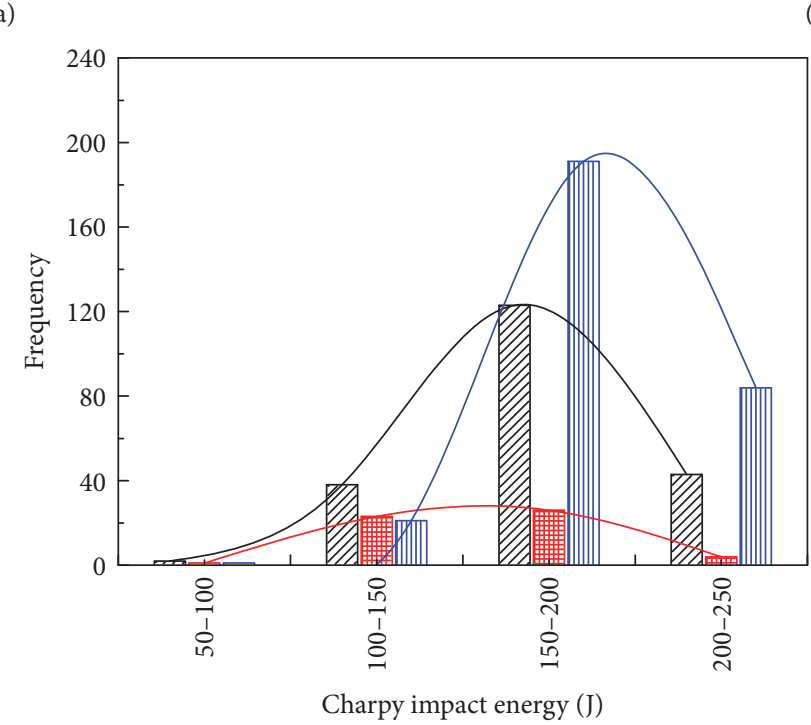

VIII Mill A: $N=206$; mean $=174$

曹冊 Mill B: $N=54$; mean $=158$

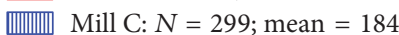

(b)

(c)

FIGURE 4: Histogram of mechanical properties of the weld joints: (a) tensile strength of weld joints; (b) Charpy impact energy of HAZs; (c) Charpy impact energy of weld metal.

(ITO) are used in the standard of X80 pipeline steel for the Second West-to-East Gas Transmission Pipeline Project to investigate the effects of $\mathrm{C}$ and alloy contents on mechanical properties of high-Nb X80 weld pipes in this work. Figure 5 shows the distribution of Ceq and $\mathrm{Pcm}$ of the steels made by the different mills. For mill A, the mean of Ceq and Pcm is low about $0.40 \%$ and $0.160 \%$, respectively, because of the low total amount of $\mathrm{Cr}, \mathrm{Ni}, \mathrm{Cu}$, or Mo (Figure 2). With the increasing of the total amount of $\mathrm{Mn}, \mathrm{Cr}, \mathrm{Ni}, \mathrm{Cu}$, or $\mathrm{Mo}$, the mean of Ceq and $\mathrm{Pcm}$ increases to $0.45 \%$ and $0.174 \%$ for mill $\mathrm{B}$ and $0.46 \%$ and $0.182 \%$ for mill $\mathrm{C}$, respectively.
Figure 6 shows the effects of the typical CE of IIW (Ceq) of the pipeline steels on the mechanical properties of pipe body and weld joint of the steel pipes. As can be seen that the strengths of pipe bodies and weld joints increase with the increasing of the Ceq, the impact toughness of pipe bodies and HAZs decreases with the increasing of the Ceq; the impact toughness of weld metals has a weak increase. However, the data of mechanical properties from different mills and batches show a high level of dispersion, so it is difficult to found clear rules. The statistical average values of mechanical properties in a range of $0.01 \%$ of Ceq 


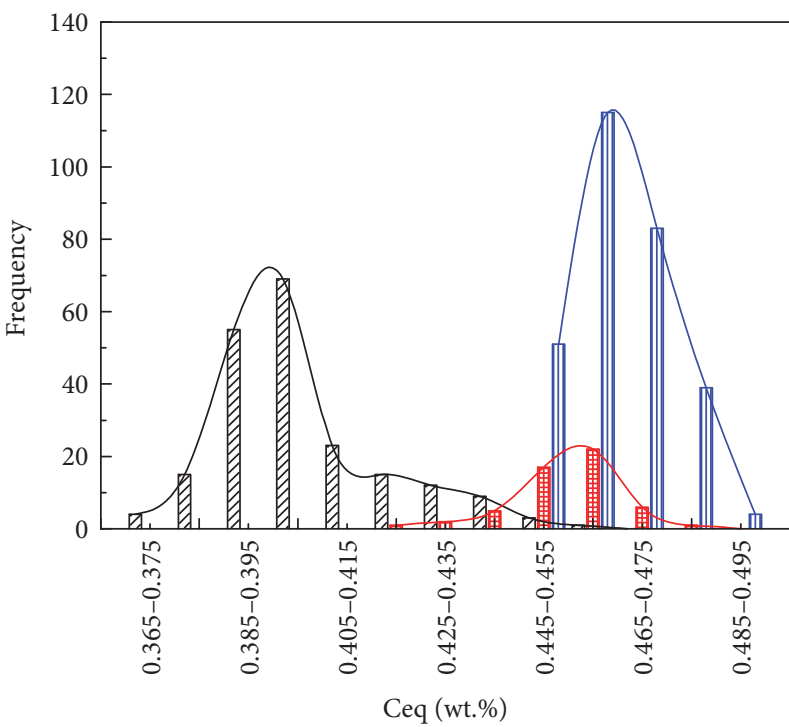

VIIII Mill A: $N=206$; mean $=0.40$ 典冊 Mill B: $N=54$; mean $=0.45$ 血血 Mill C: $N=299 ;$ mean $=0.46$

(a)

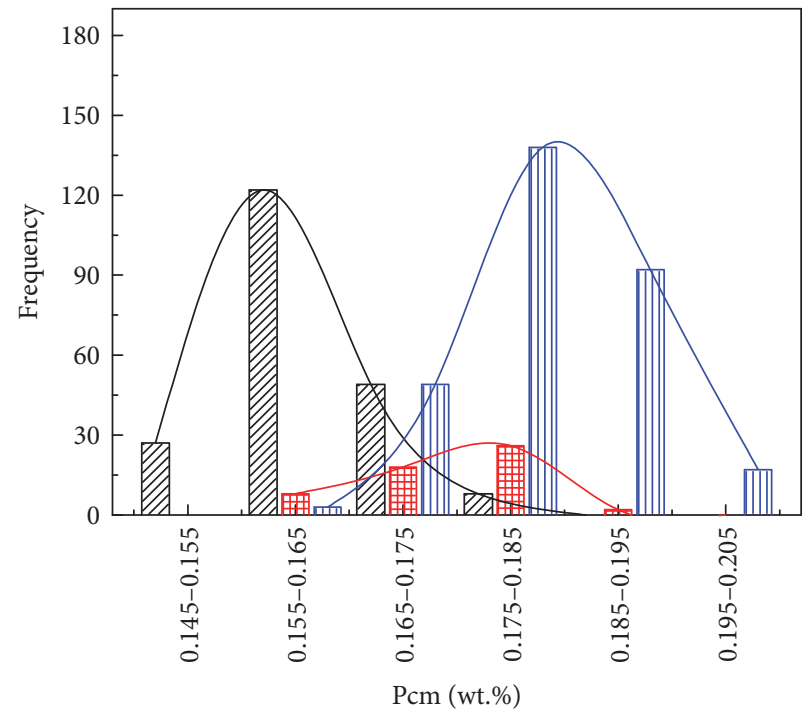

VIIIA Mill A: $N=206$; mean $=0.160$

典冊 Mill B: $N=54$; mean $=0.174$

血血 Mill C: $N=299$; mean $=0.182$

(b)

FIGURE 5: Histogram of CEs of the X80 pipeline steels from different mills: (a) Ceq; (b) Pcm.

TABle 1: The correlation of mechanical properties of pipe bodies with Ceq and Pcm.

\begin{tabular}{lccc}
\hline & Method & Relationship & Correlation \\
\hline Tensile strength (TS) & $\mathrm{Ceq}=\mathrm{C}+\frac{\mathrm{Mn}}{6}+\frac{\mathrm{Ni}+\mathrm{Cu}}{15}+\frac{\mathrm{Cr}+\mathrm{Mo}+\mathrm{V}}{5}$ & $\mathrm{TS}=501( \pm 22)+464( \pm 51) \mathrm{Ceq}$ \\
\hline $\mathrm{Pcm}=\mathrm{C}+\frac{\mathrm{Si}}{30}+\frac{\mathrm{Mn}+\mathrm{Cu}+\mathrm{Cr}}{20}+\frac{\mathrm{Ni}}{60}+\frac{\mathrm{Mo}}{15}+\frac{\mathrm{V}}{10}+5 \mathrm{~B}$ & $\mathrm{TS}=509( \pm 15)+1098( \pm 88) \mathrm{Pcm}$ \\
\hline Yield strength (YS) & $\mathrm{Ceq}=\mathrm{C}+\frac{\mathrm{Mn}}{6}+\frac{\mathrm{Ni}+\mathrm{Cu}}{15}+\frac{\mathrm{Cr}+\mathrm{Mo}+\mathrm{V}}{5}$ & $\mathrm{YS}=562( \pm 20)+154( \pm 45) \mathrm{Ceq}$ & 0.97 \\
\hline Impact energy (IE) & $\mathrm{C}+\frac{\mathrm{Si}}{30}+\frac{\mathrm{Mn}+\mathrm{Cu}+\mathrm{Cr}}{20}+\frac{\mathrm{Ni}}{60}+\frac{\mathrm{Mo}}{15}+\frac{\mathrm{V}}{10}+5 \mathrm{~B}$ & $\mathrm{YS}=555( \pm 19)+425( \pm 107) \mathrm{Pcm}$ & 0.57 \\
\hline $\mathrm{Ceq}=\mathrm{C}+\frac{\mathrm{Mn}}{6}+\frac{\mathrm{Ni}+\mathrm{Cu}}{15}+\frac{\mathrm{Cr}+\mathrm{Mo}+\mathrm{V}}{5}$ & $\mathrm{IE}=951( \pm 58)-1404( \pm 132) \mathrm{Ceq}$ & 0.79 \\
\hline
\end{tabular}

(e.g., $\mathrm{Ceq}=0.40 \pm 0.005 \%$ is in the range from $0.495 \%$ to $0.405 \%$ ) are analyzed, and the results are also illustrated in Figure 6, which can better illustrate the rules. The mechanical properties seem to present a linear relation with the Ceq (Figure 6). Therefore, the relationships of the mechanical properties of weld pipes with the Ceq are shown in Tables 1 and 2. In addition, the similar results can be found for the Pcm, and the relationships of the mechanical properties of weld pipes with the Pcm are shown in Tables 1 and 2. Of course, the different CE method is different in considering the alloyed elements and their effectiveness; the Ceq only considers the effect of $\mathrm{C}, \mathrm{Mn}, \mathrm{Ni}, \mathrm{Cu}, \mathrm{Cr}, \mathrm{Mo}$, and $\mathrm{V}$, while the $\mathrm{Pcm}$ adds the $\mathrm{Si}$ and $\mathrm{B}$. Meanwhile, the effective degrees of each alloyed element are also different between Ceq and Pcm; as a result, some differences appear in the analysis results.
For the pipe body, the tensile strength has a high linear correlation with the Ceq and $\mathrm{Pcm}$, and the correlation coefficients reach 0.88 and 0.97 , respectively; the yield strength shows lower linear correlation with the Ceq and Pcm; the correlation coefficients are only 0.57 and 0.79 . The results may attribute to the effect of TMCP. However, the results also give another implication; that is, the yield ratio decreases with the increase of the values of $\mathrm{CE}$; the slopes of tensile strength with CEs are higher than yield strength (Table 1); as a result, the yield ratio decreases. Therefore, increasing CE could help to control yield ratio of the steel pipes. The impact energy shows high linear correlation with the Ceq and Pcm, and the correlation coefficients reach 0.91 (Table 1).

For the weld joint, the same rules can be found. The correlation coefficients of tensile strength with Ceq and $\mathrm{Pcm}$ reach 0.96 and 0.98 , respectively. The correlation coefficients 

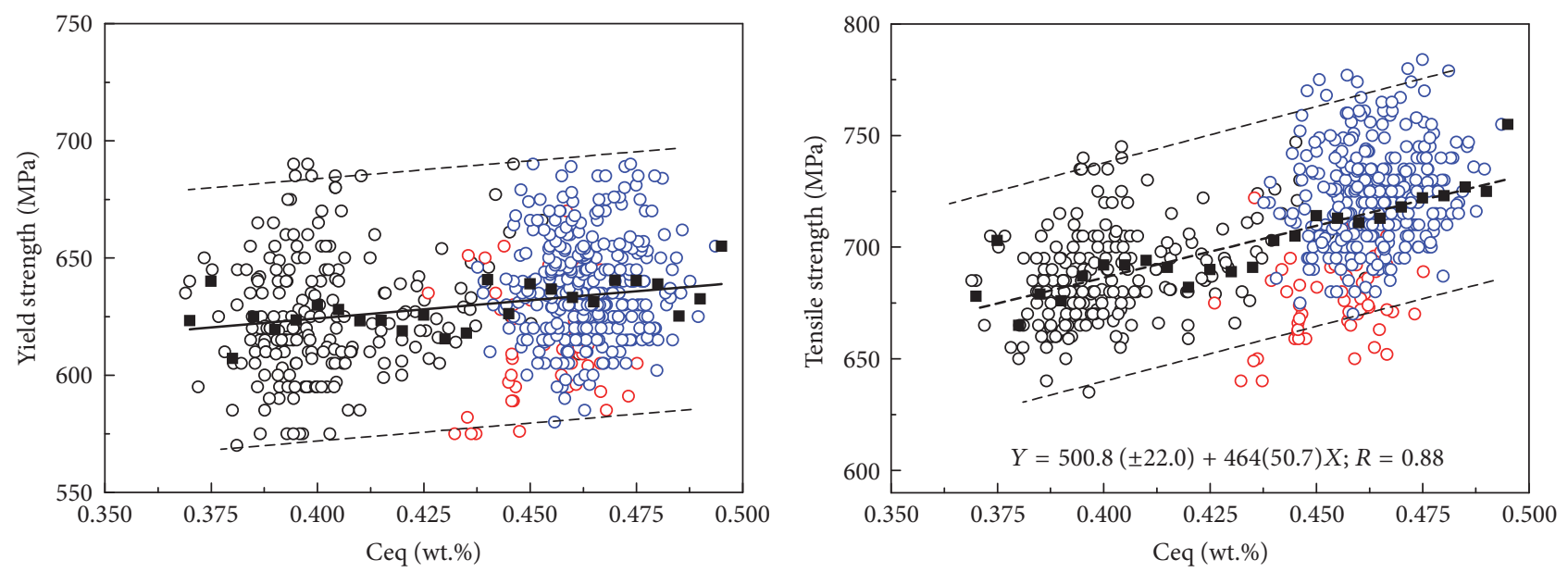
○ Mill A
- Mill B
- Mill C
- Average value

(a)

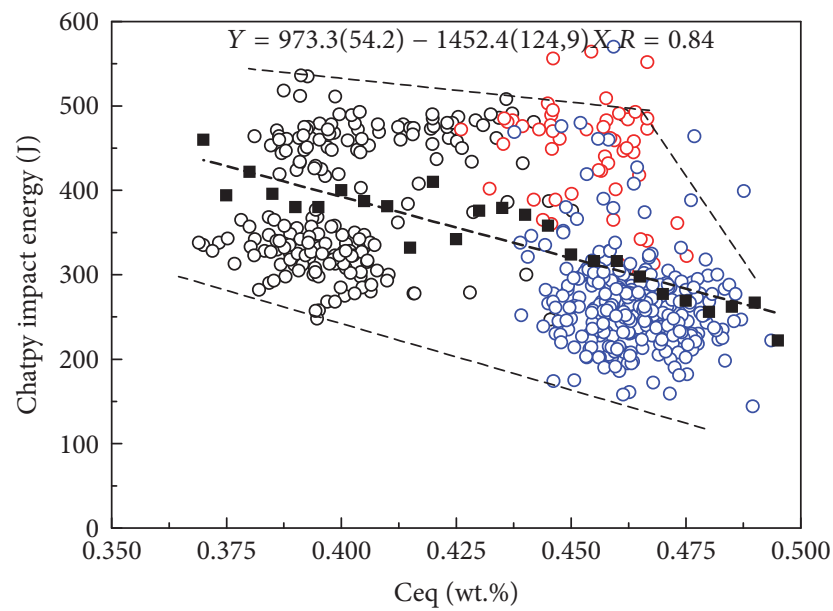

○ Mill A

○ Mill B

o Mill C

- Average value

(c)

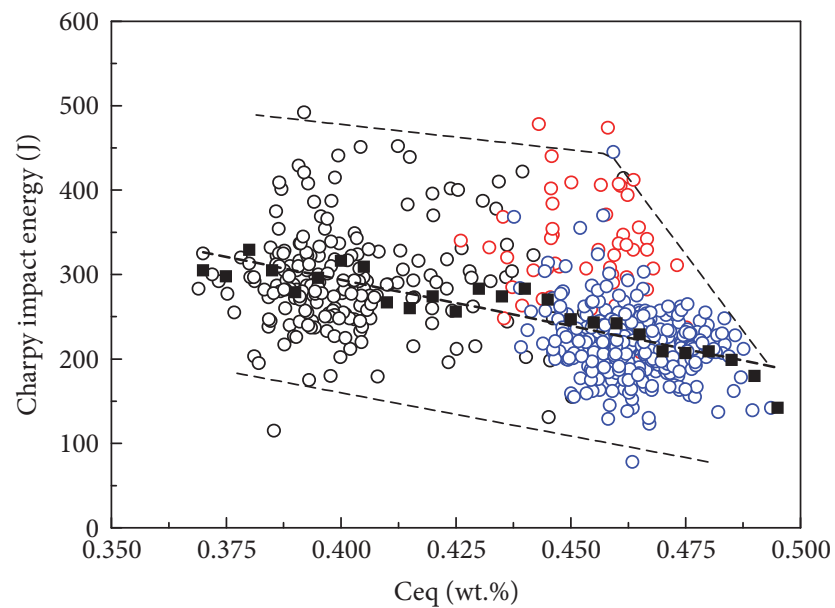

○ Mill A

- Mill B

- Mill C

- Average value

(e)
○ Mill A
- Mill B
- Mill C
- Average value

(b)

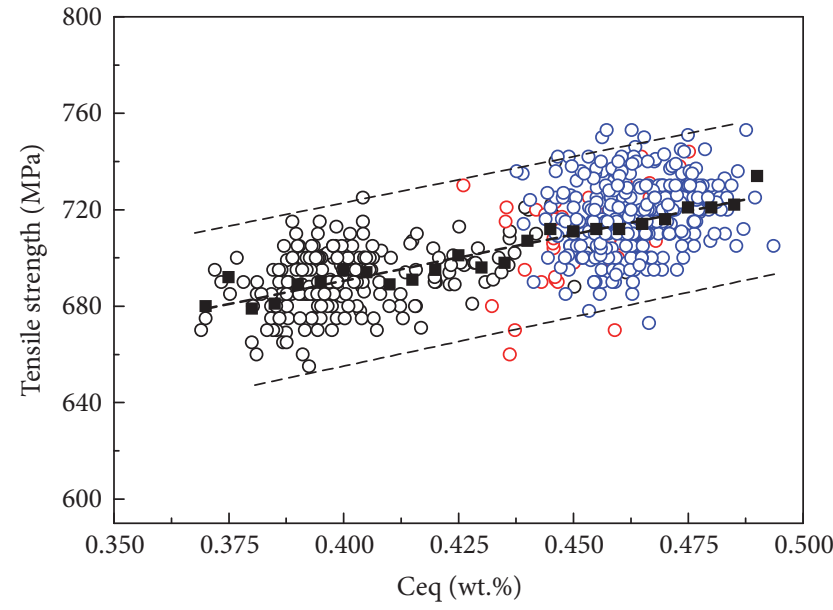

- Mill A

○ Mill B

- Mill C

- Average value

(d)

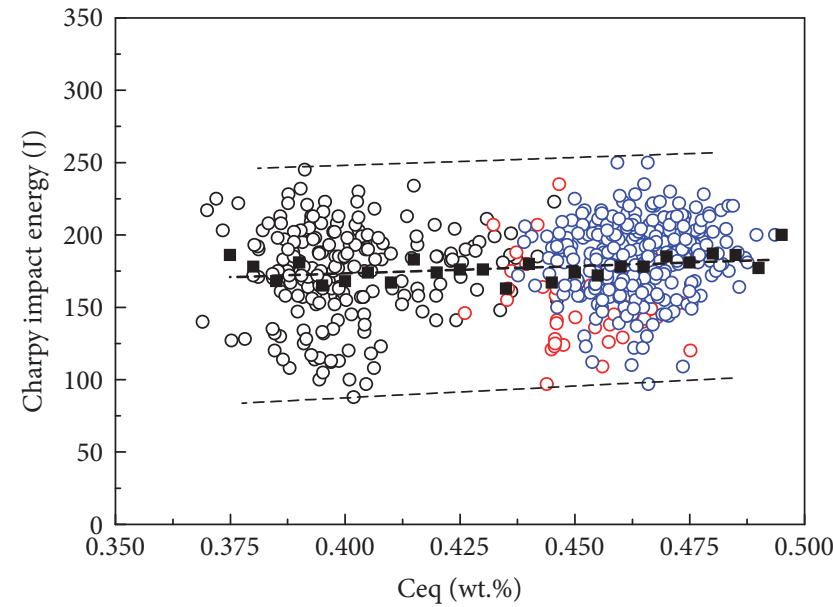

- Mill A

- Mill B

- Mill C

- Average value

(f)

Figure 6: Effects of the Ceq on the mechanical properties of the pipe body $(a-c)$ and weld joint $(e-f)$. 
TABLE 2: The correlation of mechanical properties of weld joints with Ceq and Pcm.

\begin{tabular}{|c|c|c|c|}
\hline & Method & Relationship & correlation \\
\hline \multirow{2}{*}{$\begin{array}{l}\text { Tensile strength }(\mathrm{TS}) \text { of } \\
\text { weld joint }\end{array}$} & $\mathrm{Ceq}=\mathrm{C}+\frac{\mathrm{Mn}}{6}+\frac{\mathrm{Ni}+\mathrm{Cu}}{15}+\frac{\mathrm{Cr}+\mathrm{Mo}+\mathrm{V}}{5}$ & $\mathrm{TS}=536( \pm 10)+386( \pm 24) \mathrm{Ceq}$ & 0.96 \\
\hline & $\mathrm{Pcm}=\mathrm{C}+\frac{\mathrm{Si}}{30}+\frac{\mathrm{Mn}+\mathrm{Cu}+\mathrm{Cr}}{20}+\frac{\mathrm{Ni}}{60}+\frac{\mathrm{Mo}}{15}+\frac{\mathrm{V}}{10}+5 \mathrm{~B}$ & $\mathrm{TS}=568( \pm 9)+776( \pm 48) \mathrm{Pcm}$ & 0.98 \\
\hline \multirow[t]{2}{*}{ Impact energy (IE) of HAZ } & $\mathrm{Ceq}=\mathrm{C}+\frac{\mathrm{Mn}}{6}+\frac{\mathrm{Ni}+\mathrm{Cu}}{15}+\frac{\mathrm{Cr}+\mathrm{Mo}+\mathrm{V}}{5}$ & $\mathrm{IT}=731( \pm 44)-1094( \pm 101) \mathrm{Ceq}$ & 0.91 \\
\hline & $\mathrm{Pcm}=\mathrm{C}+\frac{\mathrm{Si}}{30}+\frac{\mathrm{Mn}+\mathrm{Cu}+\mathrm{Cr}}{20}+\frac{\mathrm{Ni}}{60}+\frac{\mathrm{Mo}}{15}+\frac{\mathrm{V}}{10}+5 \mathrm{~B}$ & $\mathrm{IE}=624( \pm 42)-2099( \pm 237) \mathrm{Pcm}$ & 0.94 \\
\hline \multirow{2}{*}{$\begin{array}{l}\text { Impact energy (IE) of } \\
\text { weld metal }\end{array}$} & $\mathrm{Ceq}=\mathrm{C}+\frac{\mathrm{Mn}}{6}+\frac{\mathrm{Ni}+\mathrm{Cu}}{15}+\frac{\mathrm{Cr}+\mathrm{Mo}+\mathrm{V}}{5}$ & $\mathrm{IE}=133( \pm 19)+101( \pm 43) \mathrm{Ceq}$ & 0.44 \\
\hline & $\mathrm{Pcm}=\mathrm{C}+\frac{\mathrm{Si}}{30}+\frac{\mathrm{Mn}+\mathrm{Cu}+\mathrm{Cr}}{20}+\frac{\mathrm{Ni}}{60}+\frac{\mathrm{Mo}}{15}+\frac{\mathrm{V}}{10}+5 \mathrm{~B}$ & $\mathrm{IE}=112( \pm 15)-356( \pm 84) \mathrm{Pcm}$ & 0.81 \\
\hline
\end{tabular}

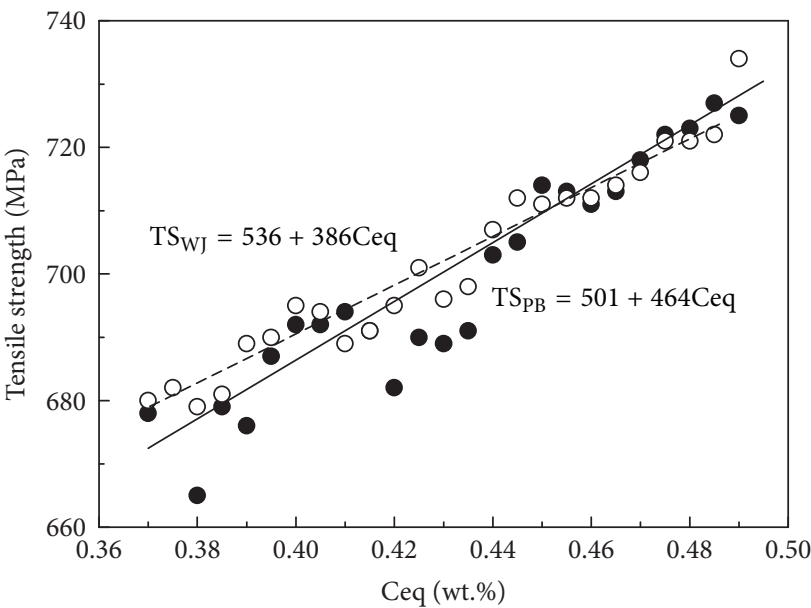

- Pipe body ○ Weld joint

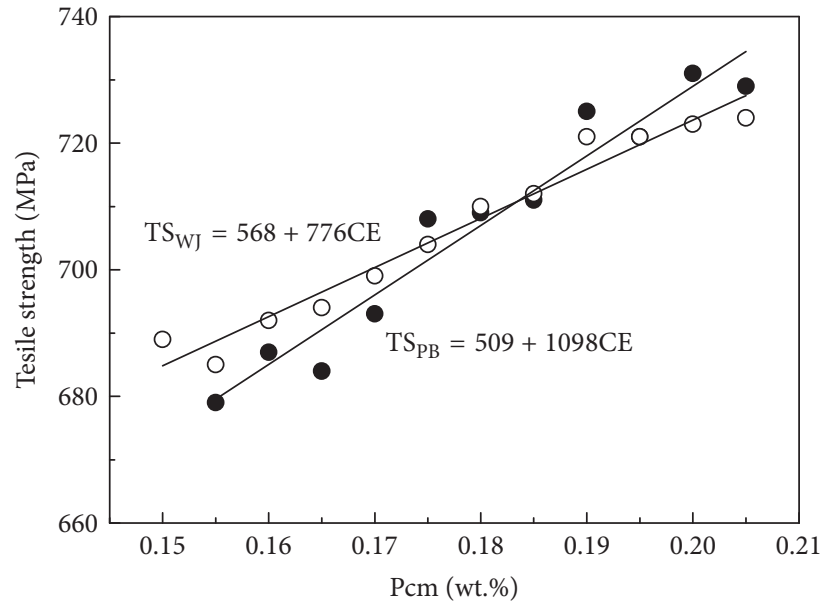

- Pipe body

○ Weld joint

(a)

(b)

Figure 7: Effects of Ceq (a) and Pcm (b) on the tensile strength of the pipe body and weld joint.

of impact toughness with Ceq and Pcm reach 0.91 and 0.94 , respectively (Table 2). Whereas the impact toughness of weld metal has lower correlation with the CEs of steels, the correlation coefficients are only 0.44 and 0.81 for Ceq and Pcm, respectively (Table 2 ).

Comparing to the pipe body, whether tensile strength or impact toughness, the correlation coefficients of weld joint are higher than the pipe body, which indicate that the CE methods are more specifically suitable to assess the weldability of steel, especially mechanical properties of HAZ. The above results indicated that the weakness of HAZ becomes a more common problem. However, from Figure 6 through Tables 1 and 2, the tensile strength of weld joint is not always lower than the pipe body, while some traits can be found. With the increasing of CEs, the increasing rate of the tensile strength of HAZ is lower than pipe body, which is clearly illustrated in Figure 7. As the Ceq and Pcm are lower than $0.45 \%$ and $0.18 \%$, respectively, the strength of the weld joints is higher than the bodies. Conversely, at higher CE values, the strength of the weld joints is lower than the bodies.
The results indicate that the strength of the high strength steels may degenerate more seriously than the low strength steels.

The best effect of the CE methods is used to appraise crack sensitivity, which affects the toughness. From the results in the work (Tables 1 and 2), the impact energy of the body and $\mathrm{HAZ}$ of pipe seems to show a higher linear correlation with the CEs. Nevertheless, a new and important phenomenon can be found in Figures 6(c) and 6(e), which is clearly illustrated in Figure 8(a). No matter pipe body or HAZ, as the Ceq is below $0.44 \%$, the impact energy shows little change with the increasing of the Ceq. On the contrary, as the value of the Ceq is over $0.44 \%$, the impact energy markedly reduces with the increasing of the Ceq. Meanwhile, the similar rules exist in the Pcm, which is also clearly illustrated in Figure 8(b). As the optimum Pcm is below $0.17 \%$, the Charpy impact energy does not show the decreasing trend with the increasing of the Pem. And with the further increase of the Pcm, the Charpy impact energy decreases quickly. The results stated that the optimal values of Ceq and Pcm exist to affect the impact toughness 


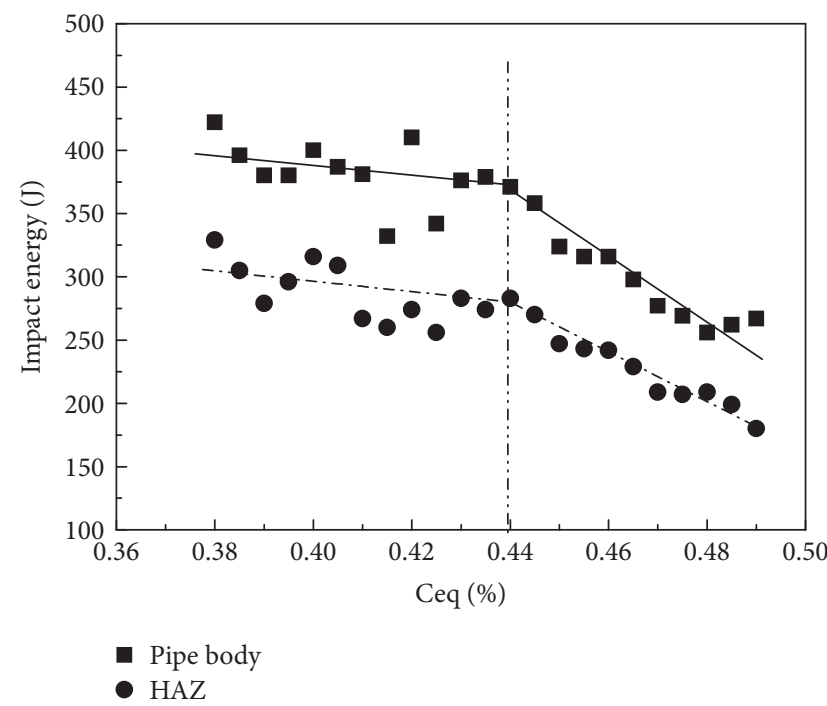

(a)

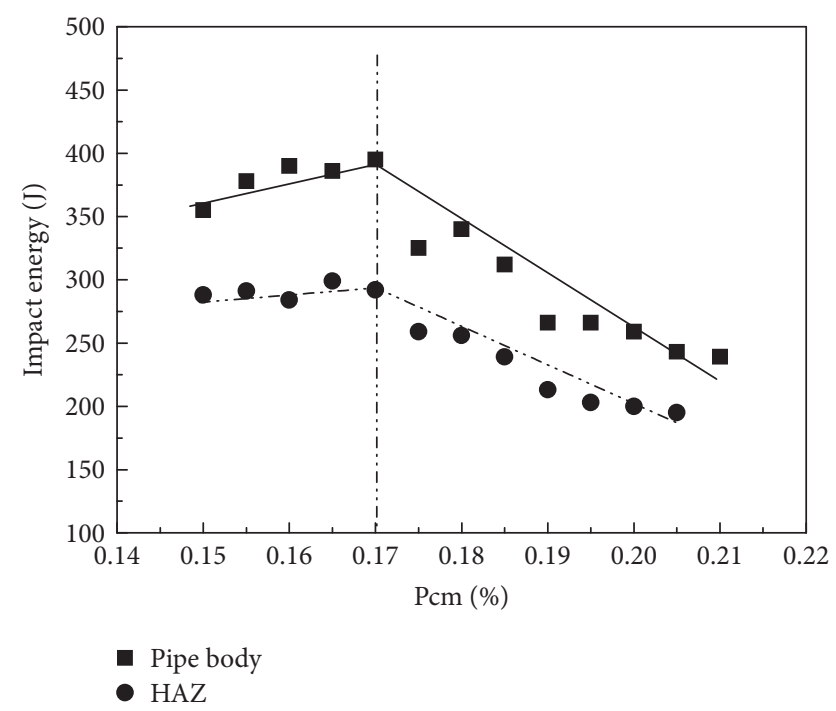

(b)

Figure 8: Effects of Ceq (a) and Pcm (b) on the impact toughness of the pipe body and weld joint.

of HAZ for the steel pipes in this work. Therefore, the impact toughness of HAZ may be improved by suitable design and control the chemical compositions of the steels

\section{Discussion}

From all the above results stated, although the mechanical properties of all pipes meet the specified requirements of the technical condition of the Longitudinal Submerged Arc Welded Pipe for the Second West-to-East Gas Pipeline Project [4] (Figures 3 and 4), some values of mechanical properties are close to the lower limit of the standard. In addition, for the weld joints, especially HAZs, either the impact toughness or the tensile strength of HAZs is lower than the pipe bodies. The lower mechanical properties and locations would strongly affect the quality of the steel pipes and the integrality and operation safety of pipeline. Therefore, how to improve the mechanical properties of the high-Nb $\mathrm{X} 80$ steel pipes becomes a key problem of production of high$\mathrm{Nb}$ X80 steel pipes.

For the pipeline steel pipes manufactured by hot rolling steel plates, JCOE, and weld, there are many factors, such as the chemical compositions of steels and TMCP and JCOE forming and welding process parameters, which affect the mechanical properties of pipe bodies and weld joints [17]. However, the statistical results from this work show that the mechanical properties of steel pipes show strong relation to the chemical compositions of steels, especially the tensile strength and impact toughness of the weld joints, although the steel plates come from different mills and design with different alloying systems (Tables 1 and 2 ). Therefore, how to design and control the chemical composition of the X80 pipeline steel becomes one of the key issues. The effects of weld process during the pipe production must be firstly considered, particularly the impact toughness.
However, as can be seen from Figures 6-8, the optimal values of Ceq and Pcm may have effect on the impact toughness of the pipe body and HAZ of the steel pipes in this work. For the pipe bodies, the impact toughness mainly depends on microstructure of steel plates. The optimal microstructure of the acicular ferrite (and/or low-carbon bainite) must be obtained by advanced TMCP processes so that to obtain the higher strength and toughness. For the high-Nb X80 pipeline steel, the higher content of $\mathrm{Nb}$ and trace Ti-bearing can assure obtaining the refined prior austenite grain during the reheating control rolling in the recentralization zone and deformed austenite grain during the control rolling in the nonrecentralization zone [18]. During the control cooling processes, the acicular ferrite and/or low-carbon bainite can be obtained at a large range of cooling rate [8]. The higher strength and toughness need a high cooling rate and low finish cooling temperature. For the steels from the different mill, the chemical composition would become an important factor to affect the microstructure and mechanical properties. Under the conditions of lower CEs, the increasing of CEs could promote the acicular ferrite and/or low-carbon bainite transformation, which improve the strength and toughness [19]. While the higher CEs would result in the increasing of the fraction of bainite, as a result, the strength increases and the impact toughness decreases [19].

For the HAZ, The microstructure would be major disruptions after welding thermal circle because the peak temperature is higher than phase temperature. The microstructure and mechanical properties of the HAZ are strongly related to the welding heat input and chemical composition of the steels $[14,16]$. Because the similar welding process parameters are adopted for the same size pipe manufactured in the mill, the chemical compositions of the pipeline steels become one of the most important factors to affect the mechanical properties of HAZ [14]. For the high-Nb X80 steels with high-Nb and bearing $\mathrm{Ti}$, the prior austenite grain 
in HAZ has lower coarse tendency, because the $(\mathrm{TiNb})(\mathrm{CN})$ precipitates are not completely dissolved during the thermal cycle [20]. The undissolved $(\mathrm{TiNb})(\mathrm{CN})$ particles in $\mathrm{Nb}$ steels can effectively restrain the austenite grain growth [20, 21]. In this case, the transformed microstructure becomes a most important factor to affect the mechanical properties of HAZ. Many previous research results indicate that the optimal microstructure with the high toughness is related to the phase transformation temperature [22]. Therefore, the suitable alloying elements added in the low-C and high$\mathrm{Nb}$ steels can fit phase transformation temperature and obtain the optimal microstructure, improving the toughness of HAZ as a consequence [22, 23]. The results from this work show that the optimal values of $\mathrm{Ceq}$ and $\mathrm{Pcm}$ for the high-Nb X80 pipeline steels are $0.44 \%$ and $0.17 \%$, respectively. Hence, taking the practical control into consideration, the Ceq and Pcm should be controlled below $0.46 \%$ and $0.18 \%$.

However, it is not only the toughness but also the strength that has great effect on the integrality and operation safety of pipeline [14, 24]. Therefore, optimizing the amount of the alloying elements for the high-Nb X80 pipeline steels needs to overall consider the effects on strength and toughness. The tensile test results of weld joints show that the fracture of the tensile samples mainly occurs at the HAZs, which indicate that the tensile strength of weld joint is mainly controlled by the strength of HAZ. The reason is that the correlation coefficients of tensile strength with Ceq and $\mathrm{Pcm}$ for weld joints are higher than pipe bodies (Tables 1 and 2 ), which results in that the microstructure and mechanical properties mainly depend on chemical composition after welding thermal cycle at same welding heat input [17, 22]. However, comparing the pipe body (Figure 3 ) and the weld joint (Figure 4), the mean tensile strength of weld joints of mills $A$ and $B$ is higher than the pipe bodies, while the mean tensile strength of weld joints of mill $\mathrm{C}$ is lower than the pipe bodies; the results are clearly illustrated in Figure 7 . When the CEs are at lower level, the tensile strength of weld joints is higher than the pipe bodies. There are so much conflicting results that the tensile fracture mainly occurs at the HAZs; besides, our previous works [19] reported that the HAZ was strongly weakened in steels with low alloyed content. The phenomenon may be attributed by the following two reasons. Firstly, there is the difference in sampling locations and test method. The plate-shaped specimens of weld joints and cylindrical specimens of pipe bodies are cut from the locations separated by 180 degrees (opposite each other) in the pipe; that is, the samples of weld joints come from the plate edges and the samples of pipe bodies come from center of the plates. The strength of plate edge is generally higher about $20 \mathrm{MPa}$ than the center of the plate [17]. Therefore, it is easy to understand the difference in the effect of CEs on tensile strength between the weld joints and pipe bodies. Secondly, the size of HAZ softened zone and the strength between plate and HAZ are different. Under the condition of the same size of HAZ softened zone, the difference in the strength between plate and HAZ greatly affects strength of weld joint. As the CEs are lower, although the softened HAZs have lower strength, the strength of steel plates is also lower, which results in that the strength of weld joints is more close to the strength of the plates. With the increasing of CEs, the strength of HAZs increases. Nevertheless, the increasing of the strength of the plates is more quick (Figure 8). As a result, the strength of weld joints is more close to the HAZs. Therefore, controlling the chemical composition and the strength of steel plates can improve the strength of weld joints. The results can be confirmed by comparing the strength of the pipes coiled by the steels from different mills (Figure 3 ). The steels from mill B have a suitable CE (Figure 5) and strength (Figure 7), and its weld joints have higher strength than the pipe bodies.

In addition, the yield ratio of pipe body is another important technology indicator, which must be less than 0.95 [4]. The CEs have an effect on yield ratio (Figure 3 and Table 1). As the CEs are lower, the yield and tensile strength of pipe bodies are low, and yield ratio is high. With the increase of CEs, the yield and tensile strength increase, whereas the increasing of tensile strength is quick than the yield strength (Table 1); as a result, the yield ratio decreases. Hence, the yield ratio of pipe body may be easier to control by increasing the CEs.

All above results show that the mechanical properties of all pipes with the different alloy systems and in large range of CEs meet the specified requirements of the technical condition of the longitudinal submerged arc welded pipe for the Second West-to-East Gas Transmission Pipeline Project [4]. However, the contents of $\mathrm{C}$ and alloyed element (i.e., CEs) have strong effects on mechanical properties of the pipes, especially the weld joint, and the effects of CEs on the impact toughness and strength are inconsistent. The decreasing of the CEs is helpful to improve the impact toughness, yet it decreases the strength and increases the yield ratio of pipe body; inversely, to improve the strength and the yield ratio of pipe body, the CEs must increase. In addition, for the same dimension pipes, there is an optimal CE value to improve the impact toughness and strength of HAZ, as well as decreasing the yield ratio. Therefore, the suitable amount of alloy elements should be adopted to obtain the balance of toughness and strength for body and weld joint of the high-Nb X80 welding pipe. Meanwhile, the design of alloy compositions must comprehensively consider not only the effect of alloy compositions on the mechanical properties and the cost of steel plate, but also the changes of mechanical properties during pipe manufacture processes, especially the mechanical properties of HAZs to improve the quality of the steel pipe and the operation safety of gas pipeline.

\section{Conclusion}

(1) The chemical composition and mechanical properties of high-Nb X80 steel pipes with a diameter of 1,219 mm and wall thicknesses of $22 \mathrm{~mm}$ are analyzed. All pipes coiled by steels manufactured by three mills and with different alloyed designs, such as $\mathrm{Mn}-\mathrm{Cr}-\mathrm{Nb}$ and $\mathrm{Mn}-\mathrm{Cr}-\mathrm{Mo}-\mathrm{Nb}$ systems, have good mechanical properties, especially the toughness, which meets the requirement of the technical conditions of the longitudinal submerged arc welded pipe for the Second West-to-East Gas Transmission Pipeline Project. 
(2) The mechanical properties of weld joint decrease dramatically, especially the impact toughness of HAZ. Comparing with the pipe body, the average impact energy of the HAZ reduces over $100 \mathrm{~J}$.

(3) The mechanical properties of the pipe body and weld joint depend on the chemical composition of the steels. With the increasing of CEs, the strength of the weld joint and pipe body rises, and the yield ratio decreases, whereas the increasing of strength of pipe body is more quick than the weld joint, and the strength of weld joint is weakened. The impact energy of the HAZ and pipe body decreases with the increasing of CEs. However, as the Ceq and Pcm are lower, $0.44 \%$ and $0.17 \%$, respectively, the decreasing rate of the impact energy of the HAZ and pipe body becomes slow.

(4) For the high-Nb X80 steel pipes, taking the effect of chemical composition of steel on mechanical properties of pipe body and weld joint into consideration, the Ceq and $\mathrm{Pcm}$ should be controlled in the range of $0.39 \%$ to $0.46 \%$ and $0.16 \%$ to $0.19 \%$, respectively.

\section{Conflicts of Interest}

The authors declare that there are no conflicts of interest regarding the publication of this paper.

\section{Authors' Contributions}

Gui-ying Qiao, Xiao-wei Chen, Xiu-lin Han, and Xu Wang designed the research and conducted the experiments; Guiying Qiao and Zhi-en Zhang prepared the draft manuscript; Bo Liao and Fu-ren Xiao supervised the project and participated in the discussions; Zhi-en Zhang and Fu-ren Xiao revised the manuscript. All authors reviewed the manuscript.

\section{Acknowledgments}

This work was supported by the Natural Science Foundation of China (Grants 51171162 and 51671164), the Natural Science Foundation and Steel and Iron Foundation of Hebei Province (Grant no. E2015203234), and the Hebei Provincial Key Technology Support Program (Grant no. 15211019D).

\section{References}

[1] J.-Q. Sun, H. Dai, and Y.-C. Zhang, "Research on mathematical model of thermal deformation resistance of X80 pipeline steel," Materials \& Design, vol. 32, no. 3, pp. 1612-1616, 2011.

[2] J.-Y. Yoo, S.-S. Ahn, D.-H. Seo, W.-H. Song, and K.-B. Kang, "New development of high grade X80 to X120 pipeline steels," Materials and Manufacturing Processes, vol. 26, no. 1, pp. 154160, 2011.

[3] L. Zheng, S. Gao, C. G. Zhang, B. Zhang, and Y. F. Li, "Development of high Nb X80 grade pipeline steel wide-thick plate used in the second west to east gas pipeline project," Welded Pipe and Tube, vol. 32, no. 4, pp. 25-29, 2009 (Chinese).

[4] CNPC. Q/SY GJX 0104-2007, "The technical conditions of the longitudinal submerged arc welded pipe for the Second Westto-East Gas Pipeline Project," Tech. Rep., China Petroleum Enterprise Standardization, 2007.
[5] CNPC. Q/SY GJX 0103-2007, “The technical conditions of the hot rolling steel plate for the Second West-to-East Gas Pipeline Project," Tech. Rep., China Petroleum Enterprise Standardization, 2007.

[6] K. Hulka, P. Brodignon, and J. M. Gray, "xperiment with low carbon HSLA steel containing 0.06-0.10 wt.\% niobium," Niobium Technical Report-No 1/04, CBMM, 2004.

[7] D. G. Stalheim, Iron and Steel (China), suppl. 40, 2005.

[8] D. G. Stalheim and S. G. Jansto, "The role of niobium in high strength oil and gas transmission linepipe steels," in in. Proceedings of the Biennial International Pipeline Conference, IPC 3(Part A), pp. 99-106, 2007.

[9] C. L. Miao, C. J. Shang, G. D. Zhang, and S. V. Subramanian, "Recrystallization and strain accumulation behaviors of high Nb-bearing line pipe steel in plate and strip rolling," Materials Science and Engineering: A Structural Materials: Properties, Microstructure and Processing, vol. 527, no. 18-19, pp. 4985-4992, 2010.

[10] X.-W. Chen, G.-Y. Qiao, X.-L. Han, X. Wang, F.-R. Xiao, and B. Liao, "Effects of $\mathrm{Mo}, \mathrm{Cr}$ and $\mathrm{Nb}$ on microstructure and mechanical properties of heat affected zone for Nb-bearing X80 pipeline steels," Materials and Corrosion, vol. 53, pp. 888-901, 2014.

[11] Z. Zhu, J. Han, and H. Li, "Influence of Heat Input on Microstructure and Toughness Properties in Simulated CGHAZ of X80 Steel Manufactured Using High-Temperature Processing," Metallurgical and Materials Transactions A: Physical Metallurgy and Materials Science, vol. 46, no. 11, pp. 5467-5475, 2015.

[12] M. Pouranvari and S. P. H. Marashi, "Critical review of automotive steels spot welding: Process, structure and properties," Science and Technology of Welding and Joining, vol. 18, no. 5, pp. 361-403, 2013.

[13] Z.-P. Zhao, G.-Y. Qiao, G.-P. Li, W.-W. Yang, B. Liao, and F.R. Xiao, "Fatigue properties of ferrite/bainite dual-phase X80 pipeline steel welded joints," Science and Technology of Welding and Joining, vol. 22, no. 3, pp. 217-226, 2017.

[14] S. K. Sharma and S. Maheshwari, "A review on welding of high strength oil and gas pipeline steels," Journal of Natural Gas Science and Engineering, vol. 38, pp. 203-217, 2017.

[15] F. S. Jaberi and A. H. Kokabi, "Influence of nickel and manganese on microstructure and mechanical properties of shielded metal arc-welded API-X80 steel," Journal of Materials Engineering and Performance, vol. 21, no. 7, pp. 1447-1454, 2012.

[16] Z. Zhu, J. Han, and H. Li, "Effect of alloy design on improving toughness for X70 steel during welding," Materials and Corrosion, vol. 88, pp. 1326-1333, 2015.

[17] X.-W. Chen, Research on strength change of plate-pipe, weldability and its optimizing of high-Nb X80 steel for the second east-east pipeline. [Doctoral, Dissert.], Yanshan University, 2013 (Chinese).

[18] Y.-B. Cao, F.-R. Xiao, G.-Y. Qiao, X.-B. Zhang, and B. Liao, "Quantitative research on effects of $\mathrm{Nb}$ on hot deformation behaviors of high-Nb microalloyed steels," Materials Science and Engineering: A Structural Materials: Properties, Microstructure and Processing, vol. 530, no. 1, pp. 277-284, 2011.

[19] F.-R. Xiao, B. Liao, Y.-Y. Shan et al., "Challenge of mechanical properties of an acicular ferrite pipeline steel," Materials Science and Engineering: A Structural Materials: Properties, Microstructure and Processing, vol. 431, no. 1-2, pp. 41-52, 2006.

[20] Y. Gu, P. Tian, X. Wang, X.-L. Han, B. Liao, and F.-R. Xiao, "Non-isothermal prior austenite grain growth of a high-Nb 
X100 pipeline steel during a simulated welding heat cycle process," Materials and Corrosion, vol. 89, pp. 589-596, 2016.

[21] K. Banerjee, M. Militzer, M. Perez, and X. Wang, "Nonisothermal austenite grain growth kinetics in a microalloyed x80 linepipe steel," Metallurgical and Materials Transactions A: Physical Metallurgy and Materials Science, vol. 41, no. 12, pp. 3161-3172, 2010.

[22] F. Heisterkamp, K. Hulka, and A. D. Batte, "Heat affected zone properties of thick section microalloyed steels - a perspective," in The Metallurgy And Qualification of Microalloyed Steel Weldments, pp. 659-681, AWS, Florida, FL, USA, 1990.

[23] X.-W. Chen, G.-Y. Qiao, X. Wang, F.-R. Xiao, and B. Liao, “Study on microstructure and mechanical properties of welding coarse grain heat-affected zone of high-Nb X80 steels," Advanced Science Letters, vol. 13, pp. 780-783, 2012.

[24] F. Mohammadi, F. F. Eliyan, and A. Alfantazi, "Corrosion of simulated weld HAZ of API X-80 pipeline steel," Corrosion Science, vol. 63, no. 12, pp. 323-333, 2012. 

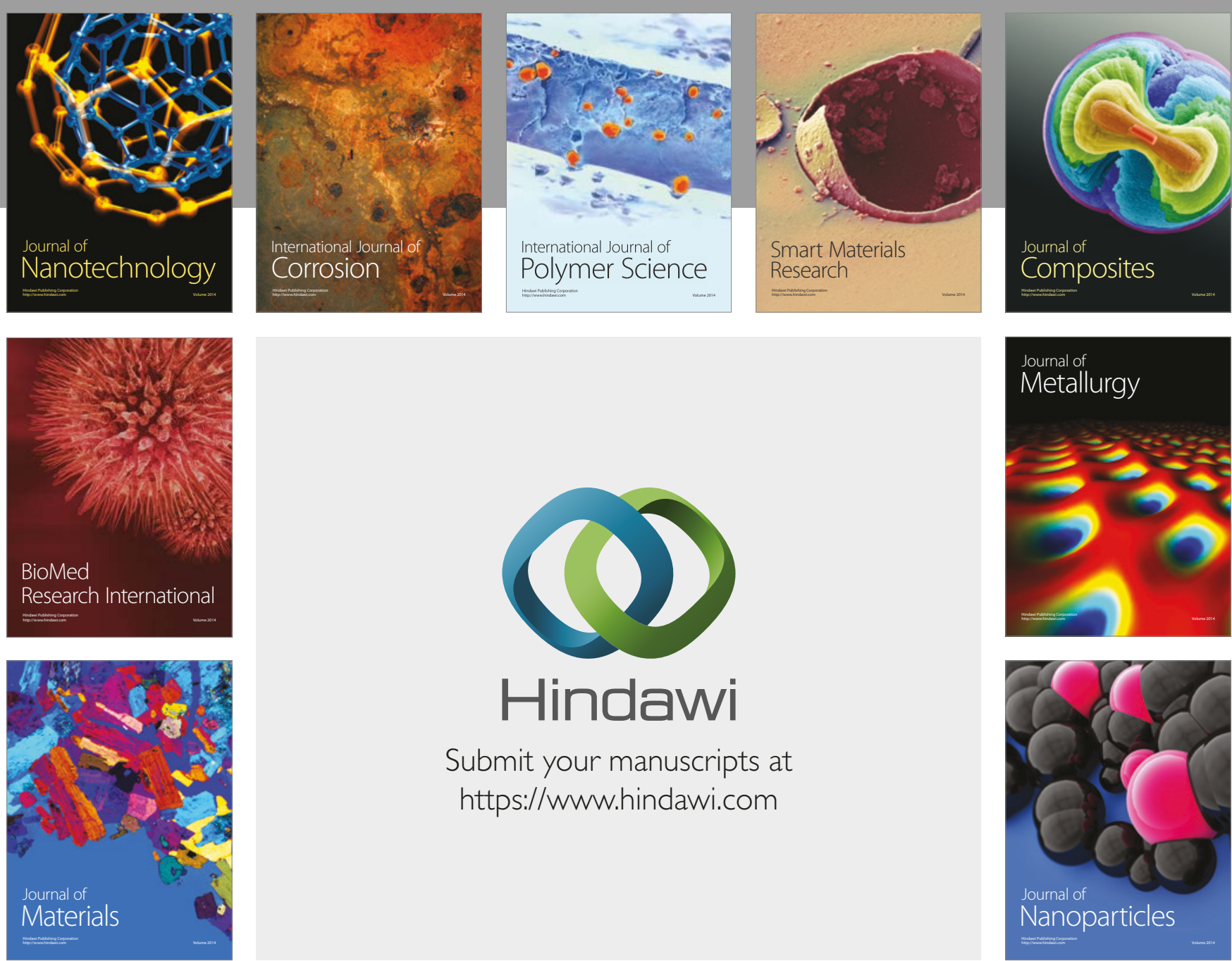

\section{Hindawi}

Submit your manuscripts at

https://www.hindawi.com
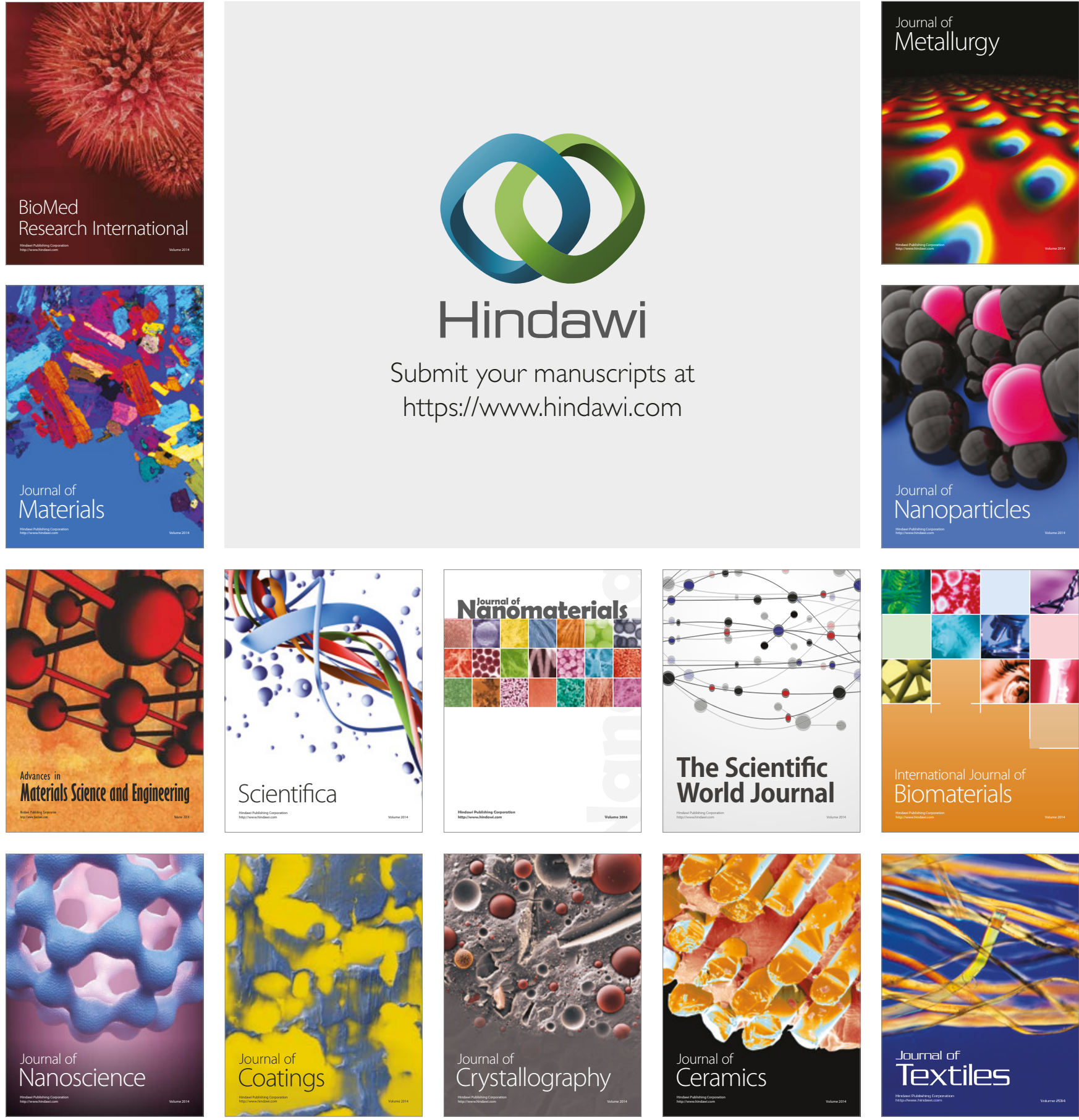

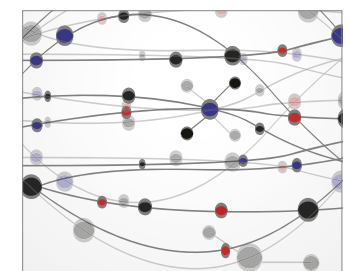

The Scientific World Journal
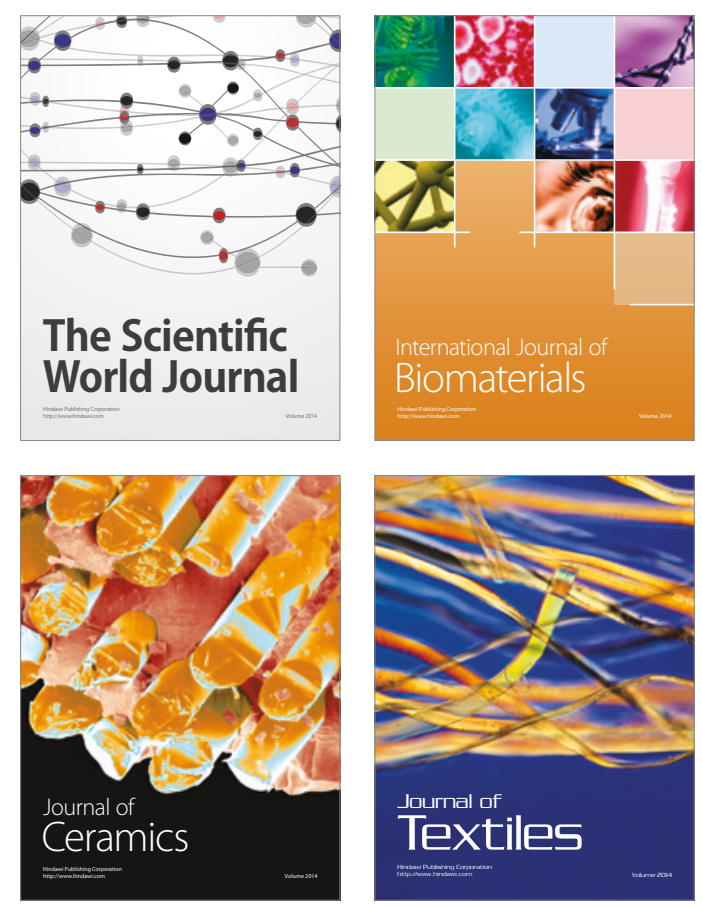